University of Nebraska - Lincoln

DigitalCommons@University of Nebraska - Lincoln

5-1-1995

Scanning tunneling microscopy study of intermediates in the dissociative adsorption of closo-1,2-dicarbadodecaborane on $\mathrm{Si}(111)$

\author{
J.M. Carpinelli \\ University of Tennessee, Knoxville \\ E. Ward Plummer \\ University of Tennessee, Knoxville, wplummer@phys.Isu.edu \\ Dongjin Byun \\ University of Nebraska-Lincoln \\ Peter A. Dowben \\ University of Nebraska-Lincoln, pdowben@unl.edu
}

Follow this and additional works at: https://digitalcommons.unl.edu/physicsdowben

Part of the Physics Commons

Carpinelli, J.M.; Plummer, E. Ward; Byun, Dongjin; and Dowben, Peter A., "Scanning tunneling microscopy study of intermediates in the dissociative adsorption of closo-1,2-dicarbadodecaborane on $\mathrm{Si}(111) "$ (1995). Peter Dowben Publications. 124.

https://digitalcommons.unl.edu/physicsdowben/124

This Article is brought to you for free and open access by the Research Papers in Physics and Astronomy at DigitalCommons@University of Nebraska - Lincoln. It has been accepted for inclusion in Peter Dowben Publications by an authorized administrator of DigitalCommons@University of Nebraska - Lincoln. 


\title{
Scanning tunneling microscopy study of intermediates in the dissociative adsorption of closo-1,2-dicarbadodecaborane on Si(111)
}

\author{
J. M. Carpinelli \\ Department of Physics and Astronomy, University of Tennessee, Knoxville, Tennessee 37996
}

E. W. Plummer

Department of Physics and Astronomy, University of Tennessee, Knoxville, Tennessee 37996 and Solid State Division, Oak Ridge National Laboratory, Oak Ridge, Tennessee 37831

Dongjin Byun and P. A. Dowben

Department of Physics, University of Nebraska, Lincoln, Nebraska 68588

(Received 27 October 1994; accepted 16 January 1995)

\begin{abstract}
Closo-1,2-dicarbadodecaborane $\left(\mathrm{C}_{2} \mathrm{~B}_{10} \mathrm{H}_{12}\right)$ is a source compound found to be suitable for the deposition of a high resistivity form of boron-carbide $\left(\mathrm{B}_{5} \mathrm{C}\right)$, and the fabrication of boron-rich semiconductor devices. A scanning tunneling microscope (STM) was used to image these molecular icosahedra on $\mathrm{Si}(111)-(7 \times 7)$. Molecular decomposition (tip induced and otherwise) produced a boron-carbide/silicon interface with pronounced heterojunction electronic characteristics. In STM, this interface is characterized by a disordering of the $\mathrm{Si}(111)-(7 \times 7)$ reconstruction. We suggest, based on Auger electron spectroscopy data and low-energy electron diffraction observations, that boron atoms from the dissociated source molecules substitutionally occupy selvedge sites, as in the boron-induced $(\sqrt{ } 3 \times \sqrt{ } 3) R 30^{\circ}$ reconstruction of $\mathrm{Si}(111)$. (C) 1995 American Vacuum Society.
\end{abstract}

\section{INTRODUCTION}

The combination of a chemical vapor deposition (CVD) source molecule and a scanning tunneling microscope (STM) has long been considered a promising route to the "direct writing" of nanostructures with varying compositions. In this process, an STM tip programmed to trace an arbitrary pattern performs like a subnanometer-resolution electron gun. The energy-tunable electron flux from this highly positionable source is used to decompose portions of a deposited layer of CVD source molecules. Further processing can afterward be applied to complete the nanofabrication process. Annealing, for example, could be employed to remove any unwanted species/undecomposed molecules through thermal desorption. The final product is a designed array of local regions with altered composition. Both organometallic compounds $^{1-4}$ and main group carboranes ${ }^{5}$ have thus far been explored as potential CVD source compounds for direct writing in an STM.

For the STM-induced dissociation to be truly a selective area deposition process, the source must adsorb molecularly, rather than dissociatively. ${ }^{5}$ In this article, we show that such a molecular precursor state exists over a limited coverage range at room temperature for the icosahedral cage molecule closo-1,2-dicarbadodecaborane $\left(\mathrm{C}_{2} \mathrm{~B}_{10} \mathrm{H}_{12}\right.$; denoted as orthocarborane in this paper). In much the same way as has been attempted for nido-decaborane ${ }^{6}$ and $\mathrm{NH}_{3}{ }^{7}$ we have studied the surface reactions of the $\operatorname{Si}(111)-(7 \times 7)$ reconstruction with orthocarborane using an STM. Spectra from the $\mathrm{B}_{5} \mathrm{C} / \mathrm{Si}(111)$ interface showing anisotropic rectifying behavior will also be presented.

\section{EXPERIMENT}

Orthocarborane is a commercially available molecule with its two carbon atoms next to each other and only exopolyhedral hydrogen atoms ${ }^{8}$ (see Fig. 1). The orthocarborane was distilled and admitted to the ultrahigh vacuum (UHV) chamber following a procedure described elsewhere. ${ }^{9}$ The final purity of the orthocarborane (Aldrich) was determined by infrared, mass spectral, and nuclear magnetic resonance measurements (purity $>98 \%$ ) and compared with literature values $;{ }^{10}$ no isomers were found to be present.

Scanning tunneling microscopy experiments were performed with the JEOL JSTM-4500VT microscopy. Normal imaging and spectroscopy set point values were $V_{\text {bias }}=+2 \mathrm{~V}$ and $I_{\text {tunnel }}=0.5 \mathrm{nA}$. Images were acquired in both the traditional "constant current" mode, as well as the "constant height" mode, where the tunneling current feedback loop responds slowly, maintaining only the average tunneling current. STM data shown were processed to remove acoustically and electronically induced noise. Low-energy electron diffraction (LEED) observations were made using conventional rear-view optics. Auger electron spectroscopy (AES) measurements were performed in a different UHV chamber using a double-pass cylindrical mirror analyzer. The substrates used in these experiments were $\mathrm{Si}(111)$ polished $n$-type wafers cut to appropriate geometries. These samples were cleaned in situ by heating to approximately $1150{ }^{\circ} \mathrm{C}$ for several seconds, while ensuring that the pressure did not rise above $1.0 \times 10^{-9}$ Torr.

\section{RESULTS AND DISCUSSION}

After a moderate (1-50 Langmuir; $1 \mathrm{~L}=1 \times 10^{-6}$ Torr s), uncalibrated dose of orthocarborane, STM imaged a series of $10-15 \AA$ diameter protrusions atop the $7 \times 7$ reconstruction of $\mathrm{Si}(111)$ as seen in Fig. 2. The average size of the observed species appears larger than the orthocarborane molecule (5.6 $\AA)$. However, this can be explained by considering that in STM images, the apparent lateral diameter of a tall protrusion is a convolution of tip shape/radius and real protrusion size. Also, it is possible that molecular clustering and some 


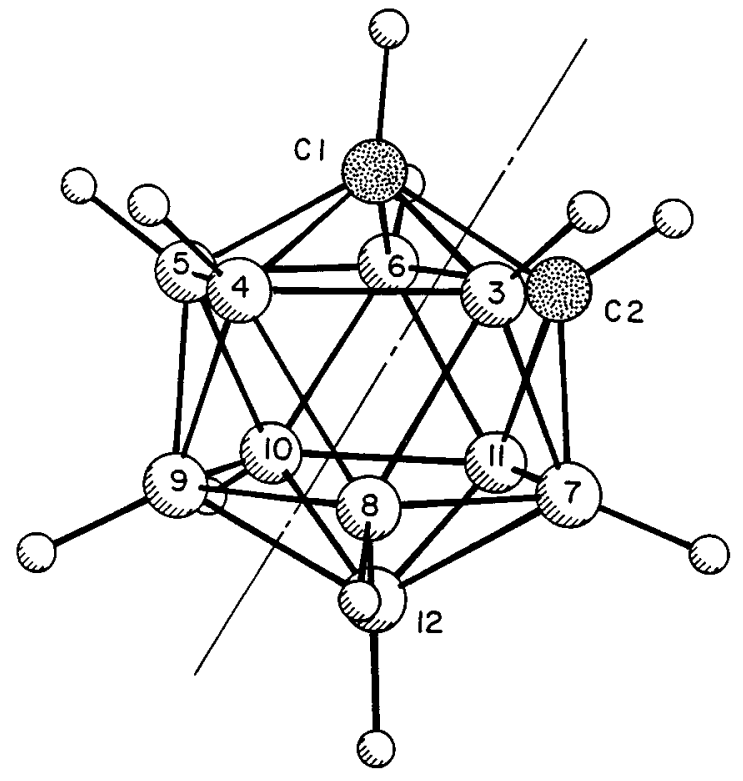

FIG. 1. Schematic diagram of closo-1,2-dicarbadodecaborane (orthocarborane), with a calculated radius of $5.6 \AA$.

fragmentation result in the variety of sizes found during imaging. Although molecular orthocarborane is believed to be only weakly bound to metal surfaces, ${ }^{9}$ the loss of only a few exopolyhedral hydrogens might substantially increase its heat of adsorption and decrease its mobility. This type of selective ligand loss has been observed with smaller carborane cage molecules. ${ }^{11}$ Decaborane decomposition studies ${ }^{12}$ suggest that hydrogen is removed as $\mathrm{H}_{2}$ in the adsorption process. The molecular icosahedral species observed is clearly a possible candidate as a precursor state to dissociative adsorption.

Concomitant with continuing orthocarborane adsorption, however, a disordering of the $\operatorname{Si}(111)-(7 \times 7)$ surface, brought about through decomposed source molecules, becomes evi-

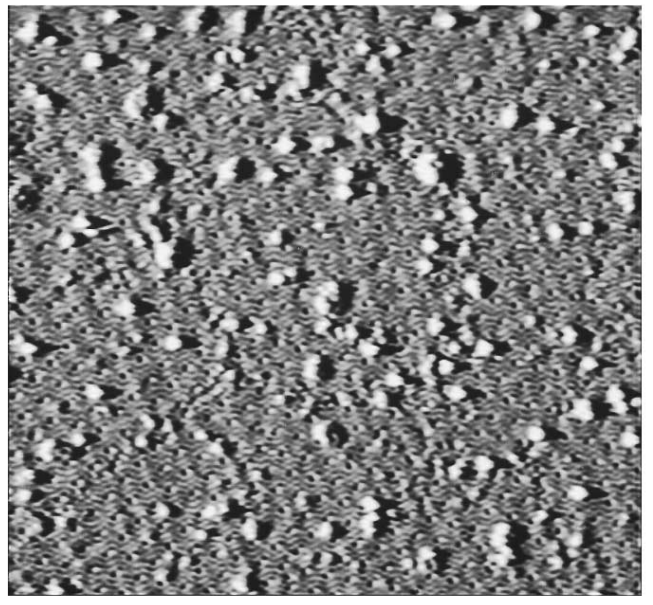

FIG. 2. $800 \times 730 \AA^{2}$ constant-height STM image of orthocarborane species atop the $\mathrm{Si}(111)-(7 \times 7)$ reconstruction.

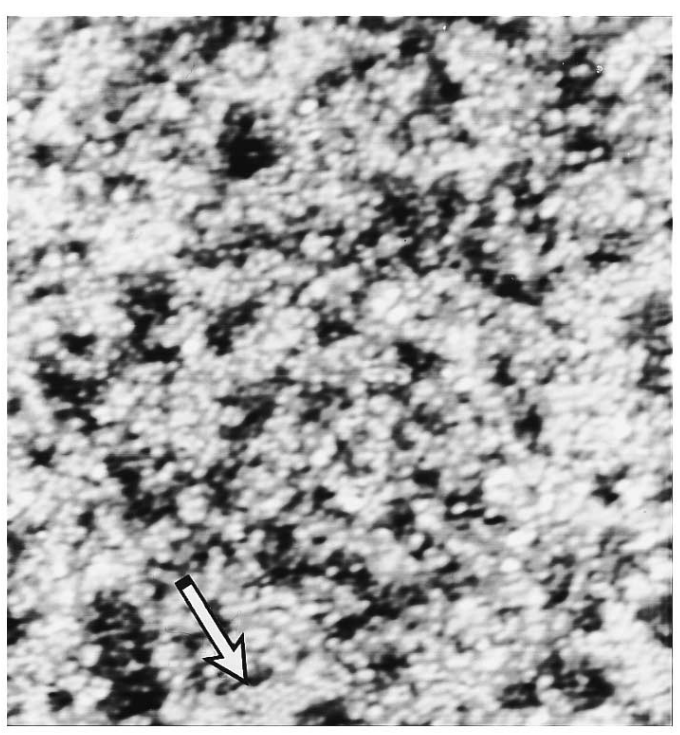

FIG. 3. $470 \times 500 \AA^{2}$ constant-current STM image of the disordered Si(111) surface following long exposure to orthocarborane. An arrow marks a region where remnants of the $7 \times 7$ unit cell can still be identified. Full height contrast in this image is $4.7 \AA$.

dent as seen in Fig. 3. While tip induced decomposition was also observed, spontaneous decomposition happened readily over time and made selective area deposition of boron carbide extremely difficult to achieve. The surface reconstruction, as recorded by STM, closely resembles the reconstruction of $\mathrm{Si}(111)$ upon exposure to decaborane. ${ }^{6}$ A number of studies have investigated the binding site for initial boron coverages. ${ }^{6,12-20}$ It is now generally accepted for initial decaborane exposures, ${ }^{6,12,17,20}$ as with other methods for forming a surface boron layer, the initial coverage of boron $(1 / 3$ monolayer) occupies the subsurface site with a coordination of $5\left(\mathrm{~S}_{5}\right)$, below a silicon surface adatom. ${ }^{6,13-17}$ A simple AES study suggests a similar mechanism for our system. Figure 4 shows the AES data for an 80 Langmuir dose of orthocarborane $\left(\mathrm{C}_{2} \mathrm{~B}_{10} \mathrm{H}_{12}\right)$ on clean $\mathrm{Si}(111)-(7 \times 7)$. The upper inset shows similar data for a film of $\mathrm{B}_{5} \mathrm{C}$. The relative intensity of the boron Auger electron feature to the carbon Auger electron feature differs substantially for these two plots, indicating the loss of some boron by either desorption or absorption. This later explanation is consistent with the surface disordering seen with STM, and our LEED observations. After rapidly heating an orthocarborane-exposed sample to approximately $800{ }^{\circ} \mathrm{C}$, weak but definite $(\sqrt{ } 3 \times \sqrt{ } 3) R 30^{\circ}$ LEED spots became visible. However, unlike the $(\sqrt{ } 3 \times \sqrt{ } 3) R 30^{\circ}$ produced with decaborane, STM observations of the surface show only clumpy disorder, most likely the result of silicon carbide formed with the two cage carbon atoms during annealing. Decaborane contains no carbon, and therefore produces a pure, well-ordered $(\sqrt{ } 3 \times \sqrt{ } 3) R 30^{\circ}$.

Local spectroscopy done with an STM gives verification of the heterojunction behavior of this boron carbide/silicon interface. Figure 5 shows three $I-V$ curves. One is from a clean $7 \times 7$ reconstruction and shows this surface's metallic character. In contrast, data from disordered regions produced 


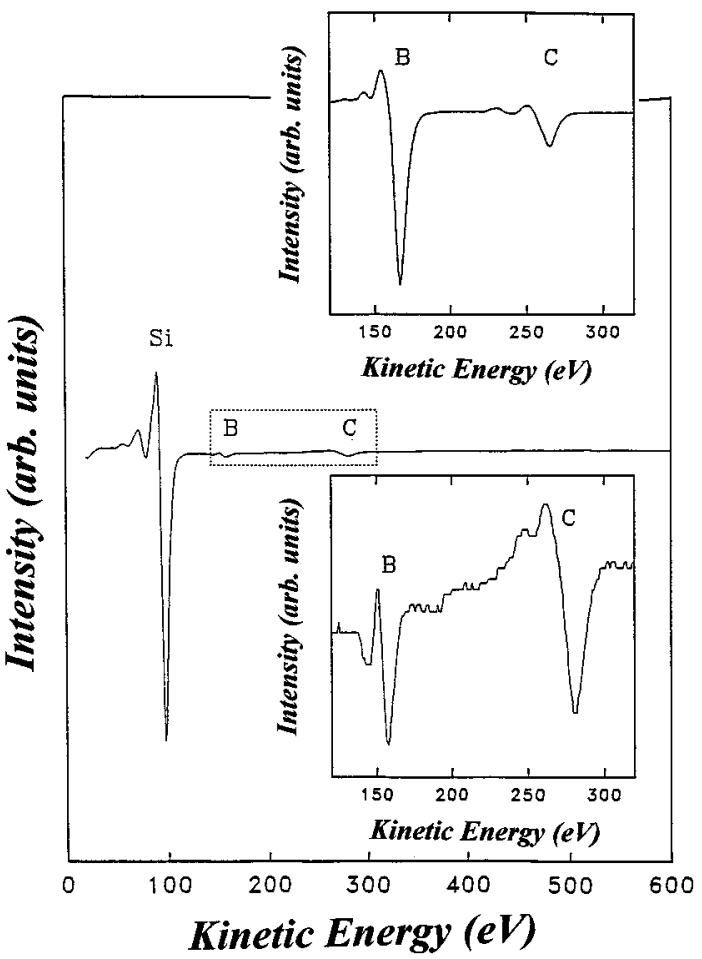

FIG. 4. An Auger electron spectrum of $\mathrm{Si}(111)$ following exposure to 80 Langmuirs orthocarborane. The bottom insert has been expanded to better show the boron and carbon lines. The top insert is a reference spectrum of $\mathrm{B}_{5} \mathrm{C}$ (Ref. 8).

upon orthocarborane decomposition show a range of anisotropy. One such $I-V$ trace is very similar to boron carbide/ $n$-Si(111) diodes formed by more conventional methods. ${ }^{21}$

The goal now is to produce localized regions with such altered electronic properties. Although orthocarborane exists initially in the molecular form on $\mathrm{Si}(111)$, and tip-induced decomposition was achieved, at room temperature decomposition unavoidably occurred over time. Therefore, further refinement of the "direct writing" procedure, including the use

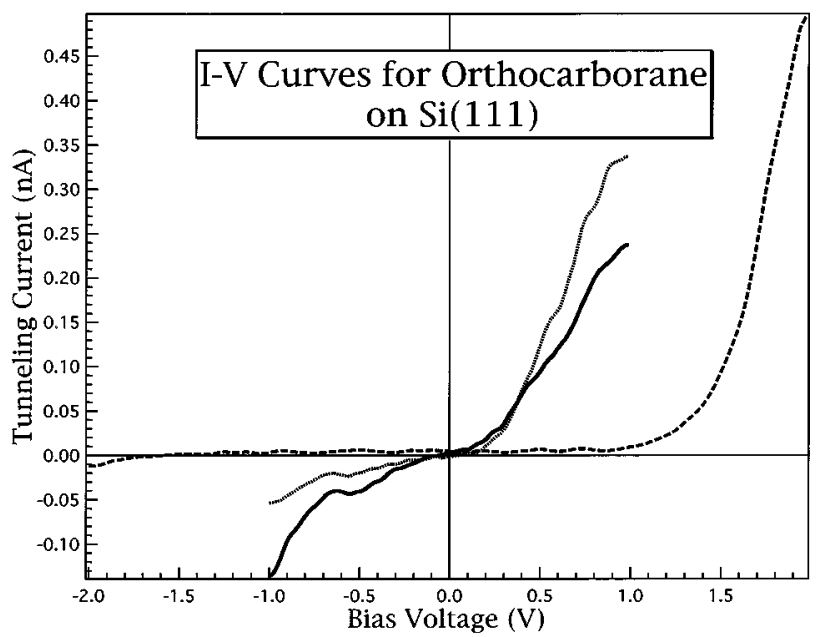

FIG. 5. $I-V$ spectra (dotted and dashed), acquired atop disordered regions where tip-induced orthocarborane decomposition has occurred, clearly show various degrees of heterojunction characteristics. Included for reference are data (solid) from the clean metallic $\mathrm{Si}(111)-(7 \times 7)$ surface. of a cold substrate for initial exposure and tunneling electron-induced decomposition, will be required to produce localized "boron-carbide diodes" surrounded by clean metallic $7 \times 7$. The results of our room-temperature efforts suggest that length scales on the order of $10 \mathrm{~nm}$ or less will be readily achievable.

\section{CONCLUSIONS}

A complex interface of a boron delta-doped silicon layer and a carbon-rich boron-carbide layer is formed at the $\mathrm{B}_{5} \mathrm{C} / \mathrm{Si}(111)$ heterojunction interface. Avoiding formation of this complex interface will require passivation of the $\mathrm{Si}(111)$ $(7 \times 7)$ reconstruction. A consequence of this complex interface is that a $\mathrm{B}_{5} \mathrm{C} / \mathrm{Si}(111)$ heterojunction may form a $p-i-n$ junction, instead of a $p$ - $n$ junction. We believe that the boron occupies a subsurface site within the silicon.

Largely complete orthocarborane icosahedral molecules can be imaged on $\mathrm{Si}(111)-(7 \times 7)$. This may be the precursor state to dissociative adsorption. The possible loss of one or two hydrogens from such species cannot, however, be excluded.

\section{ACKNOWLEDGMENTS}

This work has been funded by the AFOSR, the Research Institute of Industrial Science and Technology (RIST/Korea), and Grant No. NSF-INT-9307334. This research is also sponsored by the Division of Materials science, U.S. Department of Energy, under Contract No. DE-AC05-840R21400 with Martin Marietta Energy Systems, Inc.

${ }^{1} \mathrm{Cd}(\mathrm{Me})_{2}$ : E. E. Ehrichs, S. Yoon, and A. L. de Lozanne, Appl. Phys. Lett. 53, 2287 (1988); E. E. Ehrichs, R. M. Silver, and A. L. de Lozanne, J. Vac. Sci. Technol. A 6, 540 (1988); R. M. Silver, E. E. Ehrichs, and A. L. de Lozanne, Appl. Phys. Lett. 51, 247 (1987).

${ }^{2} \mathrm{Fe}(\mathrm{CO})_{5}$ : A. D. Kent, T. M. Shaw, S. von Molnár, and D. D. Awschalom, Science 262, 1249 (1993); M. A. McCord and D. D. Awschalom, Appl. Phys. Lett. 57, 2153 (1990); D. D. Awschalom, M. A. McCord, and G. Grinstein, Phys. Rev. Lett. 65, 783 (1990).

${ }^{3} \mathrm{Al}(\mathrm{Me})_{3}$ : E. E. Ehrich and A. L. de Lozanne, in Nanostructure Physics and Fabrication, edited by M. A. Reed and W. P. Kirk (Academic, New York, 1989), p. 441

${ }^{4} \mathrm{Pd}\left(\eta^{3}-\mathrm{C}_{3} \mathrm{H}_{5}\right)\left(\eta^{5}-\mathrm{C}_{5} \mathrm{H}_{5}\right)$ : D. S. Saulys, A. Ermakov, E. L. Garfunkel, and P. A. Dowben, J. Appl. Phys. 76, 7639 (1994).

${ }^{5} \mathrm{~B}_{10} \mathrm{H}_{14}$ : G. Dujardin, R. E. Walkup, and Ph. Avouris, Science 255, 1232 (1992); F. K. Perkins, M. Onellion, S. Lee, and P. A. Dowben, Photons and Low-Energy Particles in Surface Processing, edited by C. I. H. Ashby, J. H. Brannon, and S. W. Pang, Mater. Res. Soc. Symp. Proc. 236, 153 (1992).

${ }^{6} \mathrm{Ph}$. Avouris, J. Phys. Chem. 94, 2246 (1990); Ph. Avouris, In-Whan Lyo, F. Bozso, and E. Kaxiras, J. Vac. Sci. Technol. A 8, 3405 (1990); In-Whan Lyo, E. Kaxiras, and Ph. Avouris, Phys. Rev. Lett. 63, 1261 (1989).

${ }^{7} \mathrm{Ph}$. Avouris and R. Wolkow, Phys. Rev. B 39, 5091 (1989).

${ }^{8}$ F. Lee, P. A. Dowben, A. T. Wen, A. P. Hitchcock, J. A. Glass, and J. T. Spencer, J. Vac. Sci. Technol. A 10, 881 (1992).

${ }^{9}$ D. Byun, S.-D. Hwang, P. A. Dowben, F. K. Perkins, F. Filips, and N. J. Ianno, Appl. Phys. Lett. 64, 1968 (1994); H. Zeng, D. Byun, J. Zhang, G. Vidali, M. Onellion, and P. A. Dowben, Surf. Sci. 313, 239 (1994).

${ }^{10}$ A. P. Hitchcock, A. T. Wen, S. Lee, J. A. Glass, J. T. Spencer, and P. A. Dowben, J. Phys. Chem. 97, 8171 (1993), and the references therein.

${ }^{11}$ S. Lee, D. Li, P. A. Dowben, F. K. Perkins, M. Onellion, and J. T. Spencer, J. Am. Chem. Soc. 113, 8444 (1991).

${ }^{12}$ P. J. Chen, M. L. Colaianni, and J. T. Yates, J. Appl. Phys. 72, 3155 (1992). 
${ }^{13}$ E. Kaxiras, K. C. Pandey, F. J. Himpsel, and R. M. Tromp, Phys. Rev. B 41, 1262 (1990)

${ }^{14}$ P. Bedrossian, R. D. Mead, K. Mortensen, D. M. Chen, J. A. Golovchenko, and D. Vanderbilt, Phys. Rev. Lett. 63, 1257 (1989).

${ }^{15}$ R. L. Headrick, I. K. Robinson, E. Vlieg, and L. C. Feldman, Phys. Rev. Lett. 63, 1253 (1989).

${ }^{16}$ A. B. McLean, L. J. Terminello, and F. J. Himpsel, Phys. Rev. B 4, 7694 (1990); H. Hwang, S. Y. Tong, J. Quinn, and F. Jona, ibid. 41, 3276 (1990).
${ }^{17}$ H. H. Weitering, J. Chen, N. J. Di Nardo, and E. W. Plummer, Phys. Rev. B 48, 8119 (1993).

${ }^{18}$ Y. Ma, J. E. Rowe, E. E. Chaban, C. T. Chen, R. L. Headrich, G. M. Meigs, S. Modesti, and F. Sette, Phys. Rev. Lett. 65, 2172 (1990).

${ }^{19}$ J. E. Rowe, G. K. Wertheim, and D. M. Riffe, J. Vac. Sci. Technol. A 9, 1020 (1991).

${ }^{20}$ R. A. Rosenberg, S. P. Frigo, S. Lee, and P. A. Dowben, J. Appl. Phys. 71, 4795 (1992).

${ }^{21}$ S. Lee and P. A. Dowben, Appl. Phys. A 58, 223 (1994). 